\title{
NOVEL PROCESSING OF SILICA HYDROSOLS AND GELS
}

\author{
W.M. JONES and D.B. FISCHBACH \\ Department of Materials Science and Engineering, FB-IO, University of Washington, Seattle, WA 98195, USA
}

Received 13 November 1987

\begin{abstract}
New techniques for a solventless TEOS hydrolysis reaction and for inducing rapid homogeneous gelation with syneresis in silica hydrosols are described. The dependency of gelation time and syneresis shrinkage on the conditions at gelation are illustrated, and a reaction mechanism, based on structural considerations, is proposed. Some applications of these novel processes are suggested.
\end{abstract}

The extensive research activity on sol-gel processing of silica glass has been reviewed by several authors [1-4]. The typical alkoxide route to silica sols comprises the catalyzed reaction of tetraethoxysilane (TEOS) and water in a mutual solvent. The TEOS alkoxy groups hydrolyze to form silanol monomers which condense and crosslink to form the silica gel network. The nature of the sol and the resultant gel is determined by reactant concentrations and the type and amount of catalyst (acid or base) [5]. Special additives [6] or elaborate drying procedures [7] are generally required to obtain gel monoliths. It has long been held [8] and is now commonly assumed that a mutual solvent (e.g., a short-chain alcohol) is essential for sol formation because TEOS and water are immiscible. However, direct reaction of water with tetramethoxysilane [9], or with TEOS under intense ultrasonication [10], have been reported.

We describe here a novel technique for producing silica hydrosols from TEOS without either solvent addition or intensive agitation; and a procedure for inducing rapid and homogeneous hydrosol gelation with syneresis that yields xerogel monoliths on simple air drying [11].

In the solventless hydrosol procedure, as-received TEOS $*$ is added to distilled water and stirred magnetically to form a gray two-phase

* 99\% grade, Alfa Chemicals, Danvers, MA, USA. dispersion at room temperature. The molar ratio $R_{\mathrm{w}}$ of water to TEOS can range from about 5 to $>100$. When no catalyst is present, no significant reaction is apparent over a period of several hours. However, when the mixture is acidified with $\mathrm{HNO}$, an exothermic reaction ensues after a brief $(\sim 15 \mathrm{~s})$ induction period, and the dispersion transforms to a clear solution within $20 \mathrm{~min}$ or

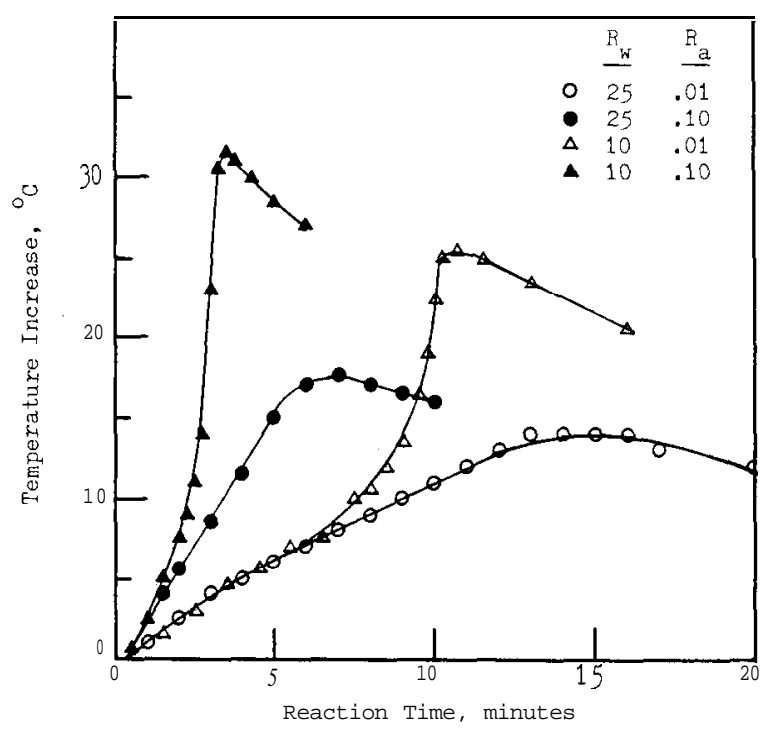

Fig. 1. Temperature-time profiles for solventless hydrosol reaction showing the effect of $R_{\mathrm{w}}=\left[\mathrm{H}_{2} \mathrm{O}\right] /[\mathrm{TEOS}]$ and $R_{\mathrm{a}}=$ $\left[\mathrm{HNO}_{3}\right] /[\mathrm{TEOS}]$. Catalyst added at $0 \mathrm{~mm}$; initial $T=25^{\circ} \mathrm{C}$; uninsulated vessel. 
less. The molar ratio $R_{\mathrm{a}}$ of acid to TEOS is typically $0.01-0.1$. The temperature-time profiles for representative combinations of $R_{\mathrm{w}}$ and $R_{\mathrm{a}}$, reacted in an uninsulated vessel, are shown in fig. 1. The reaction rate increases rapidly with catalyst concentration, and the initial rates are approximately the same for different $R_{\mathrm{w}}$ with the same $R_{\mathrm{a}}$ value. However, at high TEOS concentration $(\boldsymbol{R},=10)$ autoacceleration of the rate is evident as the reaction proceeds.

Depending on concentration, these hydrosols will gel spontaneously at room temperature in anywhere from several days to several weeks. A novel "quick-set" process was developed to obtain rapid gelation. This comprises adjustment of the sol $\mathrm{pH}$ with dilute ammonium hydroxide $(0.10 \mathrm{M})$. The molar ratio $R_{\mathrm{b}}$ of base to TEOS was varied from 0.01 to 0.07 . Gelation to a homogeneous body occurred within a few min after $\mathrm{pH}$ adjustment at room temperature. For concentrated sols, it was followed immediately by syneresis (gel shrinkage with expulsion of entrained liquor).

Both gelation time, $t_{\mathrm{gel}}$, and syneresis shrinkage depend on the amount of base addition $\left(R_{\mathrm{b}}\right)$ and on sol concentration as shown in figs. 2 and 3. The relationship of $t_{\text {gel }}$ to $R_{\mathrm{b}}$ is depicted in fig. 2 for two sols $\left(R,=10\right.$ and $\left.25 ; R_{\mathrm{a}}=0.01\right)$. The sol concentrations were adjusted to be the same at gelation $\left(5.63 \mathrm{~g} \mathrm{SiO}_{2} / 100 \mathrm{~mL}\right) . t_{\text {gel }}$ is independent of the initial $R_{\mathrm{w}}$, and has a minimum ( $\sim 2 \mathrm{~min}$ ) at $R_{\mathrm{b}}$ corresponding to $\mathrm{pH} \sim 6$ at this concentration. At constant $R_{\mathrm{b}}, t_{\mathrm{gel}}$ decreases with increasing $\mathrm{SiO}_{2}$ content, and with increasing temperature, as shown in fig. 3. Firm gels are formed at high concentration and lower $R_{\mathrm{b}}$, while dilute and more basic sols form soft gels that harden as they age.

There is a correlation between syneresis behavior and the conditions at gelation. Syneresis does not occur at low sol concentrations $(\leqslant 4 \mathrm{~g}$ $\left.\mathrm{SiO}_{2} / 100 \mathrm{ml}\right)$ or low base additions $\left(R_{\mathrm{b}} \leqslant 0.015\right)$.

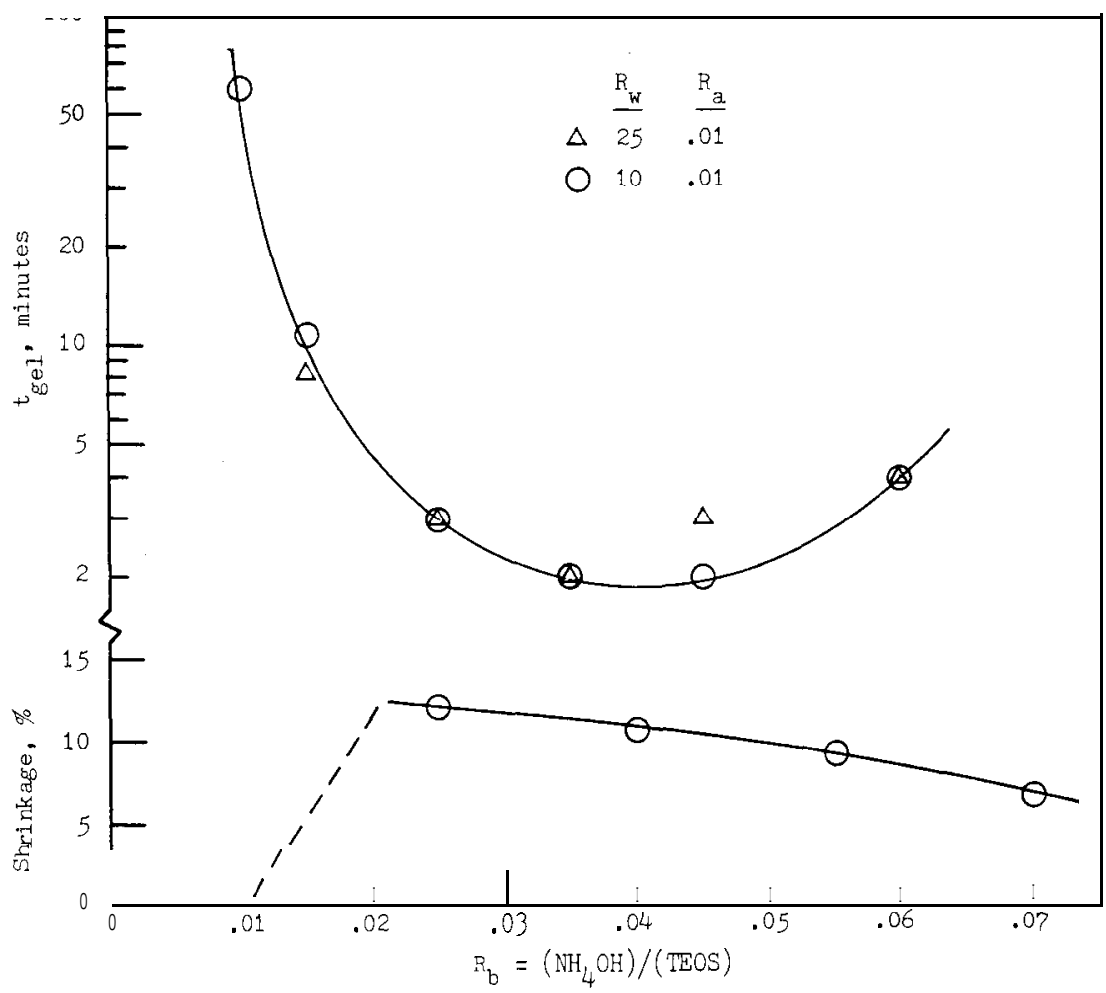

Fig. 2. Gelation time and syneresis (diametral shrinkage) of solventless hydrosols as a function of base addition, $R$,. For the syneresis data the final sol concentration was $6.99 \mathrm{~g} \mathrm{SiO}_{2} / 100 \mathrm{ml}$; for the two sets of $t_{\text {gel }}$ measurements the concentration was adjusted to 5.63. $T=25^{\circ} \mathrm{C}$. 


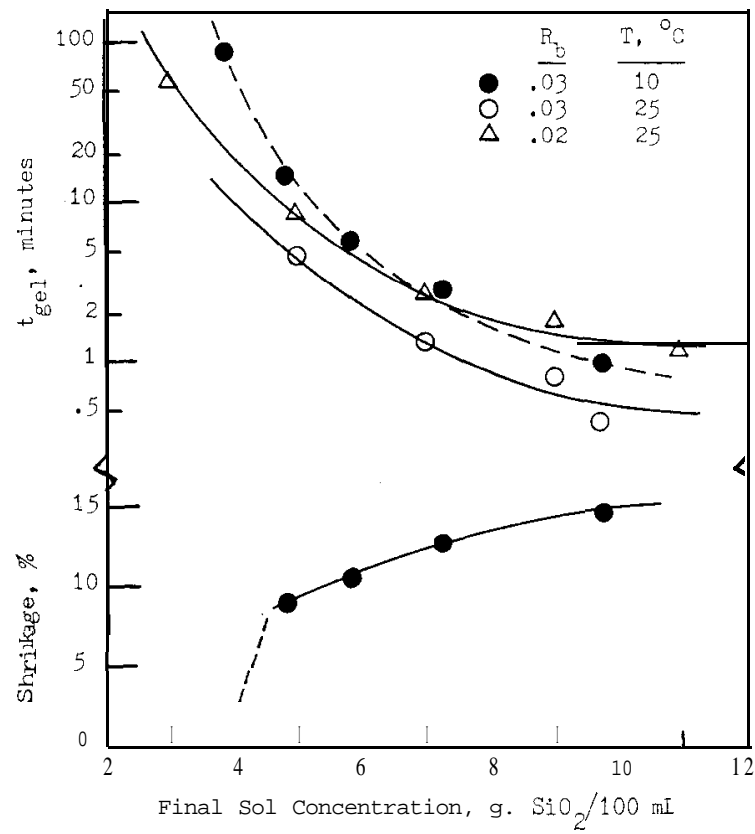

Fig. 3. Gelation time and syneresis (diametral shrinkage) of solventless hydrosols as a function of sol concentration at gelation. $R_{\mathrm{W}}=10, R_{\mathrm{a}}=0.01$.

It develops suddenly when these thresholds are exceeded. Thereafter, shrinkage decreases with increasing $R_{\mathrm{b}}$ (fig. 2) and increases with increasing $\mathrm{SiO}_{2}$ content (fig. 3). The equilibrium wet volume is attained in a few hours.

Although no solvent is added to prepare the hydrosol, ethanol is generated by hydrolysis of TEOS, facilitating the interfacial reaction [9]. This may contribute, with the increased solubility of the silanol products and the exothermic temperature rise, to the accelerating reaction rates evident at high TEOS concentrations (fig. 1). The liquor expelled from a quick-set gel $\left(R,=10 ; R_{\mathrm{b}}=\right.$ $0.025)$ was flammable and had a specific gravity corresponding to 44.8 w/o ethanol. General reaction mechanisms for the solventless hydrosol and rapid gelation processes may be hypothesized on the basis of concepts developed by Brinker et al. [12-14] and our observations. The conditions of the initial hydrosol reaction (acid catalyst, excess $\mathrm{H}_{2} \mathrm{O}$ ) favor nearly complete hydrolysis of TEOS and generation of highly-branched, weakly-crosslinked clusters which interpenetrate slightly prior to gelation. The excess water acts to inhibit the condensation reaction, and in the absence of $\mathrm{pH}$ adjustment gelation occurs by gradual linking of the discrete clusters, with no syneresis. After base is added to induce gelation, condensation between the ends and the middle sites of the chains is favored. This can result in "back-biting" of the interpenetrated chains, resulting in collapse of the gel structure and syneresis as the clusters pack together,

Cluster interpenetration and packing decreases as the sol is diluted until, below some critical concentration, syneresis cannot occur (fig. 3). In more concentrated sols, a critical $\mathrm{pH}$ must be exceeded to induce the reactions that cause gel collapse. However, further increases in base addition cause increasing deprotonation of silanols within the chains. The resulting electrostatic repulsion may reduce the packing of the collapsing clusters, producing softer gels and decreased syneresis (fig. 2).

Some aspects of the syneresis behavior of the quick-set silica gels seem to resemble the phase transition characteristics of polyacrylamide gels studied by Tanaka [15-17]. He observed reversible collapses in gel volume resulting from small changes in liquid composition or temperature. Reversibility of silica gel syneresis has not been investigated, and the observed volume change is relatively small $(\leqslant 50 \%)$; but there are sharp thresholds of composition and base addition, and shrinkage depends on concentration and $\mathrm{pH}$. Schaefer [18] suggested that changing the $\mathrm{pH}$ of a silica system could induce phase separation, and he speculated that large pore size gels might be obtained by a procedure similar to our quick-set process.

The characteristics of the quick-set gel process suggest a number of applications, and we have explored several of them. The wet gels can be infiltrated by liquid exchange with solvents or metal salt solutions to alter the drying behavior and composition. The wet gel structure can be altered by adjusting the $\mathrm{pH}$ of the exudate; the gels dissolve (or depolymerize) in strong base. Monoliths of specific gravity $\sim 1.6$ can be prepared by simple air drying of unaltered gels; they remain transparent after calcining at $600{ }^{\circ} \mathrm{C}$. Uni- 
form dispersions of short reinforcement fibers in the hydrosol are retained during rapid gelation to form homogeneous composites.

In summary, mixtures of TEOS and water react readily, under the stimulation of an acid catalyst and the ethanol produced by the hydrolysis, to form a silica sol. Rapid gelation followed by syneresis can be induced in such sols, Rapid gelation followed by syneresis can be induced in such sols, when the silica concentration exceeds a threshold level, by adjusting the $\mathrm{pH}$ with a dilute base. Several ways in which the characteristics of the quick-set gel process may be exploited have been noted.

\section{References}

[1] J. Zarzycki, in: Glass Science and Technology, Vol. 2, Processing I, eds. D.R. Uhlmann and N.J. Kreidl (Academic Press, New York, 1984) p. 209.

[2] S. Sakka, Am. Cer. Soc. Bull. 64 [11] (1985) 1463.

[3] E.M. Rabinovich, J. Mat. Sci. 20 (1985) 4259.

[4] L.C. Klein, Ann. Rev. Mat. Sci. 15 (1985) 227.

[5] K.D. Keefer, in: Better Ceramics Through Chemistry, eds.
C..J. Brinker, D.E. Clark and D.R. Ulrich (Elsevier, Amsterdam, New York, 1984) p. 15.

[6] G. Orcel and L.L. Hench, Cer. Eng. Sci. Proc. 5 (1984) 546.

[7] J. Zarzycki, M. Prassas and J. Phalippou, J. Mat. Sci. 17 (1982) 3371.

[8] A. Aelion, A. Loebel and F. Eirich, J. Am. Chem. Soc. 72 (1950) 5705.

[9] D. Avnir and V.R. Kaufman, J. Non-Cryst. Solids 92 (1987) 180.

[10] M. Tarasevich, Am. Cer. Soc. Bull. 63 (3) (1984) 500 (abstract only).

[11] W.W. Jones and D.B. Fischbach, presented at 39th Pacific Coast Meeting, Am. Ceram. Soc., Seattle, Oct 22-24, 1986.

[12] C.J. Brinker, K.D. Keefer, D.W. Schaefer and C.S. Ashley, J. Non-Cryst. Solids 48 (1982) 47.

[13] C.J. Brinker, K.D. Keefer, D.W. Schaefer, R.A. Assink, B.D. Kay and C.S. Ashley, J. Non-Cryst. Solids 63 (1984) 45.

[14] C.J. Brinker and G.W. Scherer, J. Non-Cryst. Solids 70 (1985) 301

[15] T. Tanaka, Phys. Rev. Lett. 40 (12) (1978) 820.

[16] T. Tanaka, D. Fillmore, S.-T. Sun, I. Nishio, G. Swislow and A. Shah, Phys. Rev. Lett. 45 (20) (1980) 1636.

[17] T. Tanaka, Sci. Amer. 245 (1) (1981) 124.

[18] D.W. Schaefer and K.D. Keefer, in: Better Ceramics Through Chemistry, eds. C.J. Brinker, D.E. Clark, D.R. Ulrich (Elsevier, Amsterdam, New York, 1984) p. 1. 